\title{
Reproductive consequences of developmental phytoestrogen exposure
}

\author{
Wendy $\mathrm{N}$ Jefferson, Heather B Patisaul ${ }^{1}$ and Carmen J Williams \\ Reproductive Medicine Group, Laboratory of Reproductive and Developmental Toxicology, National Institute of \\ Environmental Health Sciences, National Institutes of Health, NIEHS/NIH/DHHS, PO Box 12233, MD E4-05, \\ Research Triangle Park, North Carolina 27709, USA and ${ }^{1}$ Department of Biology, North Carolina State University, \\ Raleigh, North Carolina 27695, USA
}

Correspondence should be addressed to CJWilliams; Email: williamsc5@niehs.nih.gov

\begin{abstract}
Phytoestrogens, estrogenic compounds derived from plants, are ubiquitous in human and animal diets. These chemicals are generally much less potent than estradiol but act via similar mechanisms. The most common source of phytoestrogen exposure to humans is soybean-derived foods that are rich in the isoflavones genistein and daidzein. These isoflavones are also found at relatively high levels in soy-based infant formulas. Phytoestrogens have been promoted as healthy alternatives to synthetic estrogens and are found in many dietary supplements. The aim of this review is to examine the evidence that phytoestrogen exposure, particularly in the developmentally sensitive periods of life, has consequences for future reproductive health.

Reproduction (2012) 143 247-260
\end{abstract}

\section{Introduction}

Phytoestrogens are plant compounds that are structurally similar to estradiol and can interact with estrogen receptors (ERs) to promote and/or inhibit estrogenic responses. These compounds are ingested as part of a normal diet and are frequently included in plantbased dietary supplements such as those advertised to alleviate symptoms of menopause. The major phytoestrogen groups are isoflavones (genistein, daidzein, glycitein, and formononetin), flavones (luteolin), coumestans (coumestrol), stilbenes (resveratrol), and lignans (secoisolariciresinol, matairesinol, pinoresinol, and lariciresinol) (Moutsatsou 2007). Isoflavones are found at high concentrations in soybean products whereas lignans are found in flax seed, coumestans are found in clover, and stilbenes are found in cocoa- and grape-containing products, particularly red wine. The $\beta$-D-glycoside form of genistein - genistin - makes up the majority $(55-65 \%)$ of the isoflavone content in soy products (Setchell et al. 1997). The $\beta$-D-glycoside form of daidzein - daidzin - comprises about $30-35 \%$, and glycitin, glycitein, biochanin $\mathrm{A}$, and formononetin together account for $<10 \%$ of soy isoflavones. For additional reference regarding dietary isoflavone content, see the USDA-lowa State University Database on the Isoflavone Content of Foods (release 1.3, U.S. Department of Agriculture, Beltsville, MD, USA) at
http://www.nal.usda.gov/fnic/foodcomp/Data/isoflav/ isoflav.html and Thompson et al. (2006).

Several decades ago, observational studies raised concerns regarding the reproductive toxicity of phytoestrogens consumed in the diet. The earliest evidence that naturally occurring phytoestrogens could cause reproductive disturbances in mammals was reported in 1946, indicating that sheep that grazed on red clover were infertile due to the estrogenic content in the clover (Bennetts et al. 1946, Morley et al. 1966). About 20 years later, a similar observation was made in cows that had fertility disturbances resulting from periods of stallfeeding on red clover (Kallela et al. 1984). Finally, a population of captive cheetahs exhibited infertility while eating soy-based diets (Setchell et al. 1987). In all three cases, fertility was restored when the phytoestrogen intake was reduced. Similarly, abnormalities in reproductive health due to high intake of soy products have been reported in several women (Amsterdam et al. 2005, Chandrareddy et al. 2008). These observations demonstrate that dietary phytoestrogens can have adverse effects on reproductive function in adults.

Organ systems in developing animals are typically more sensitive to chemical exposures than in adults. In fact, extensive tissue morphogenesis and differentiation of organs important for reproductive function occur both pre- and postnatally. Many of these differentiation events are dependent, at least in part, on steroid hormone 
signaling (Young et al. 1964, MacLusky \& Naftolin 1981, Park \& Jameson 2005, Ma 2009, Sakuma 2009). For this reason, endocrine-disrupting chemicals, including phytoestrogens, could have a significant impact on development in ways that affect later reproductive health. Furthermore, these effects could have long-term consequences for the offspring of the affected individuals.

Since the initial observations of adverse effects of phytoestrogens on adult mammalian reproductive health, numerous studies have been performed in laboratory animal models to evaluate the estrogenic activity of phytoestrogens (Diel et al. 2000, Jefferson et al. 2002) and their effects on development and reproduction. Most studies have been performed in rodent models, with various phytoestrogens administered either prenatally to the pregnant dam or postnatally to the pups (Burroughs et al. 1990b, Medlock et al. 1995b, Nagao et al. 2001, Newbold et al. 2001, Kouki et al. 2003, Nikaido et al. 2004, Jefferson et al. 2005, Bateman \& Patisaul 2008). Together, these studies provide a wealth of evidence that exposure of developing animals to phytoestrogens negatively impacts future fertility. We present here background information regarding human phytoestrogen exposure that provides the rationale for studies in animal models and briefly review the mechanisms of phytoestrogen action and the critical concept of specific windows of developmental sensitivity to disruption. We then review in detail the information regarding phytoestrogens and reproductive health outcomes, focusing mainly on studies of developmental phytoestrogen exposure in animal model systems, and concluding with available information from human studies.

\section{Human phytoestrogen exposure}

The amount of phytoestrogens consumed in the diet is highly variable and depends primarily on soy consumption; the resulting serum circulating levels of phytoestrogens are also highly variable (Verkasalo et al. 2001). For example, the highest circulating levels of genistein are seen in Asian populations who traditionally consume high levels of soy; Japanese men and women have $\sim 500 \mathrm{nM}$ genistein in circulation (Adlercreutz et al. 1994, Morton et al. 2002). There is also a large range of soy consumption across Europe. One study found mean serum genistein levels of $148 \mathrm{nM}$ in a region with many vegetarians and much lower mean levels (2.6-22.6 nM) in other regions where fewer vegetarians lived (Peeters et al. 2007). This variability was also seen in another European study in which subjects were divided into four groups based on the amount of reported dietary soy intake (lowest to highest) and the corresponding serum genistein levels were 14.3, 16.5, 119, and $378 \mathrm{nM}$ (Verkasalo et al. 2001). Serum genistein levels in Finnish omnivores and vegetarians were 4.9 and $17.1 \mathrm{nM}$, respectively (Adlercreutz et al. 1994). Americans, in general, have low levels of genistein because soy is not prevalent in the diet. A nonrepresentative subset of samples from the National Health and Nutrition Examination Survey showed an average serum genistein level of $17.4 \mathrm{nM}$, with about half of the samples tested having nondetectable levels (Valentin-Blasini et al. 2003).

Because of maternal dietary phytoestrogen consumption, human fetuses are exposed to phytoestrogens during in utero development (Franke et al. 1998, Foster et al. 2002). The fetus is exposed to substances in maternal serum through the filter of the placenta. Although in theory the placenta serves as a barrier to protect the fetus from exposure to harmful chemicals, in fact most drugs and environmental chemicals enter the fetal circulation by either passive diffusion or active transport (Syme et al. 2004). An important modifier of fetal exposure is binding of chemicals to maternal serum proteins. For example, human steroid hormone-binding protein (SHBG) binds estradiol with high affinity and likely protects the fetus from the effects of maternal estradiol on the brain and reproductive tract. However, human pregnancy plasma, which includes SHBG, has negligible affinity for phytoestrogens (Milligan et al. 1998); so fetal exposure to phytoestrogens is directly related to the maternal serum circulating level. The fetal counterpart to serum albumin is $\alpha$-fetoprotein (AFP), the major serum constituent in the fetus. In rodents, AFP efficiently binds estradiol and could also serve to protect the fetus from its developmental effects. However, human AFP does not bind estradiol (Keel et al. 1992), and neither type of AFP binds phytoestrogens, and so the presence of AFP in human fetal serum is not protective. Indeed, genistein and daidzein are detected in amniotic fluid from the second trimester of pregnancy at levels similar to those observed in adult serum, and 10- to 20-fold higher than the average amniotic fluid estradiol levels at that time of pregnancy (Robinson et al. 1977, Foster et al. 2002).

Although human infants can be exposed to phytoestrogens via breast milk (Franke et al. 1998), the highest human exposure to phytoestrogens occurs in infants consuming soy-based infant formulas (Setchell et al. 1997, Cao et al. 2009). Infants fed exclusively soy-based formula have serum genistein levels of 1-10 $\mu \mathrm{M}$ when tested at random time intervals after feeding (Cao et al. 2009). Differences in the time of serum collection after feeding may explain the $\sim 10$-fold difference in values from different individuals. The estrogenic activity of soy-based formula in human infants was documented recently in a largely cross-sectional study of the plausible effects of estrogen exposure on male and female infants fed breast milk, soy formula, or cow milk formula (Bernbaum et al. 2008). Vaginal/introital wall cells in all the girls showed estrogen effects at birth, which were largely lost by about 3 months. The two girls fed soy formula and studied at 6 months showed re-estrogenization (Fig. 1). This small study is consistent with an estrogen 


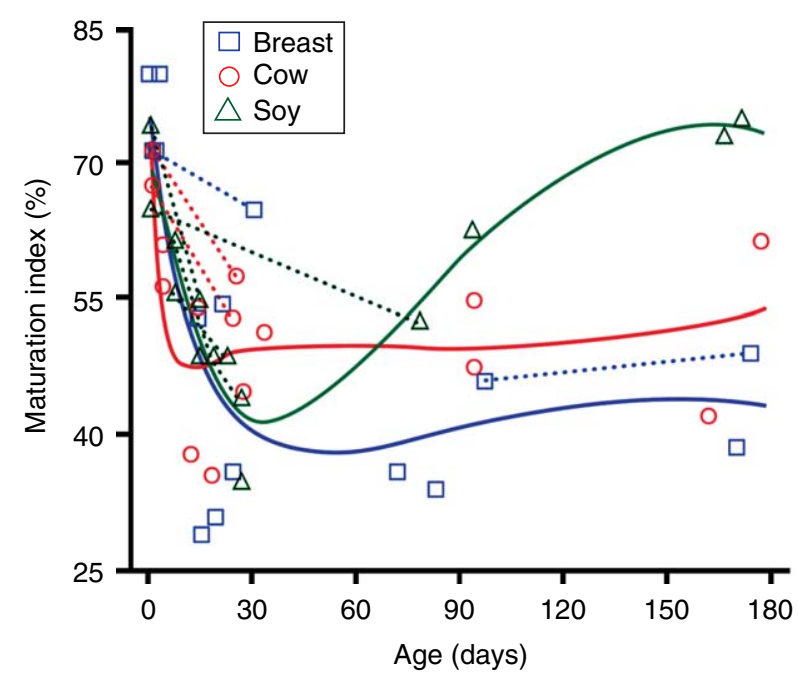

Figure 1 Maturation index of vaginal wall cells over time in infants fed breast milk, cow-based formula, or soy-based formula. Maturation index is expressed as the percent of superficial cells plus half of the percent of intermediate cells on a Papanicolaou smear of vaginal introitus cells from female infants. Solid curves extrapolated from data obtained from 11 or 12 infants per group. Dotted line segments connect observations from multiple visits by the same child at different ages. Figure adapted with permission from Environmental Health Perspectives; Bernbaum et al. (2008).

effect from the soy formula, and suggests that further study of this simple and interpretable endpoint is worthwhile.

\section{Relevance of animal models to human exposure levels}

Ideally, studies to examine the effects of phytoestrogens on humans could be conducted in human subjects. However, there is wide variation in human exposures, these exposures are difficult to measure accurately, and the exposures are inherently difficult to control effectively (Verkasalo et al. 2001). There is also extensive variability in the phytoestrogen content of many dietary sources over time, whether standard food products or commercial botanical extracts that are sold as dietary supplements (Thompson et al. 2006). Furthermore, not all humans metabolize phytoestrogens in the same way because of differences in the activity of metabolizing enzymes and the influence of gut microflora on phytoestrogen bioavailability (de Cremoux et al. 2010). Together, these factors complicate both design and interpretation of human studies, and combined with the ethical issues regarding experimentation in humans, have led to extensive reliance on studies that utilize animal models.

The relevance to human health of studies performed in animal models has been questioned because in many of the animal studies exposure to phytoestrogens was by a non-oral route, whereas most human phytoestrogen exposure is due to dietary intake (Verkasalo et al. 2001). Non-oral exposures are frequently chosen for rodent models of developmental phytoestrogen exposure because the size difference between rodents and humans, particularly in the neonatal period, precludes achieving similar serum phytoestrogen levels by an oral exposure route. Given that the serum concentration determines the amount of bioactive chemical to reach a target tissue, we believe that the serum measurement is the most important parameter to consider when attempting to model human exposures. This idea has been substantiated for genistein in two recent publications where direct comparisons of biological effects were made after exposure via different routes and forms of the chemical (Jefferson et al. 2009a, Cimafranca et al. 2010).

Pharmacokinetic analyses of s.c. exposure of neonatal mice to genistein and oral exposure to genistin or genistein demonstrated that oral exposure to genistin results in peak circulating levels of total genistein that are higher than those following s.c. injection, but the total area under the curve over a 24 -h period is very similar (Fig. 2; Jefferson et al. 2009a). Both exposure methods result in similar biological effects, suggesting that both peak and sustained genistein levels contribute to biological outcomes. In contrast, following an orally administered dose of genistein, there is $\sim 90 \%$ less genistein found in circulation when compared with the same dose of genistein administered s.c., and about a 20-fold lower peak genistein level (Jefferson et al. 2009a). Genistein also has much lower bioavailability than genistin when given orally to adult rats (Kwon et al. 2007). These data confirm that oral genistein dosing results in significantly lower tissue bioavailability when compared with both oral genistin exposure and s.c. genistein exposure. Furthermore, both oral genistin and s.c. genistein dosing in this neonatal mouse model system result in low micromolar serum circulating total genistein levels that closely approximate the levels measured in infants fed soy-based infant formula (Fig. 2; Cao et al. 2009, Jefferson et al. 2009a). These findings support their use in modeling developmental exposure of human infants to phytoestrogens.

\section{Mechanisms of phytoestrogen action}

The mechanisms of action of various phytoestrogens have been reviewed recently (Dang 2009, Li \& Tollefsbol 2010, Lorand et al. 2010, Shanle \& Xu 2011) and therefore will only be mentioned briefly here. As the name implies, phytoestrogens can interact with the classical estrogen receptors, ER $\alpha$ and ER $\beta$, which mediate many of their downstream actions. Their affinities for $E R \alpha$ and $E R \beta$ are relatively weak compared with estradiol, and they can have agonist or antagonist activity depending on whether estradiol is also present (Shanle \& Xu 2011). This is in contrast to the well-known endocrine-disrupting chemical diethylstilbestrol (DES), 


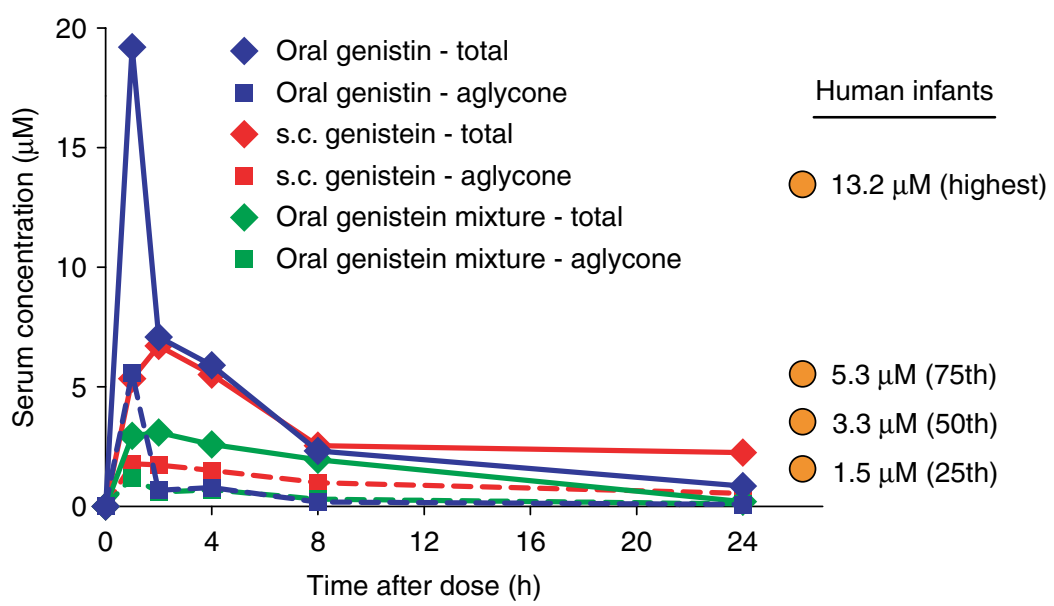

Figure 2 Serum circulating levels of genistein following neonatal exposure by different routes. Data plotted are mean serum genistein levels at the indicated times after dosing. Blue lines, oral genistin $37.5 \mathrm{mg} / \mathrm{kg}$ in corn oil, data from Jefferson et al. (2009a); red lines, subcutaneous (SQ) genistein $50 \mathrm{mg} / \mathrm{kg}$ in corn oil, data from Doerge et al. (2002); green lines, oral genistein $50 \mathrm{mg} / \mathrm{kg}$ in soy formula/corn oil mixture, data from Cimafranca et al. (2010). Total serum genistein shown in solid lines; aglycone fraction shown in dotted lines. Single orange points on the right side of the graph are the 25th, 50th, 75th percentiles and highest level of total serum genistein in human infants fed soy formula at random time points after feeding, data from Cao et al. (2009).

which has higher affinity than estradiol for the ERs that mediate the majority of its actions (Korach \& McLachlan 1985, Shanle \& Xu 2011). Several phytoestrogens are selective ER modulators that have greater affinity for ER $\beta$ than ER $\alpha$ (Lorand et al. 2010). However, phytoestrogens and xenoestrogens such as DES also affect numerous other signaling pathways including nongenomic signaling mediated by oxidative stress pathways, tyrosine kinases, nuclear factor- $\kappa \mathrm{B}$, and extracellular signalregulated kinases (Watson et al. 2007, de Souza et al. 2010). In addition to classical ERs, phytoestrogens serve as ligands for peroxisome proliferator-activated receptors, the nonclassical ER GPER1 (previously GPR30), the estrogen-related receptors, and the aryl hydrocarbon receptor (Suetsugi et al. 2003, Dang 2009, Prossnitz \& Barton 2009, de Souza et al. 2010). Besides direct actions to modulate signaling pathways, phytoestrogens can alter epigenetic marks by altering the activities of DNA and histone methyltransferases, NAD-dependent histone deacetylases, and other modifiers of chromatin structure (Labinskyy et al. 2006, Li \& Tollefsbol 2010, Shanle \& Xu 2011). Finally, phytoestrogens can competitively inhibit the production of estradiol by aromatase (Kao et al. 1998, Shanle \& Xu 2011), which would lead to lower endogenous estrogen levels. The complexity of phytoestrogen actions is increased by the fact that these compounds are frequently present in vivo as mixtures of several dietary components that can affect multiple signaling pathways or affect the same pathways in opposing directions.

\section{Windows of developmental sensitivity}

The fetus and neonate are highly sensitive to environmental chemical exposures because organogenesis, rapid growth, and extensive tissue differentiation occur during these developmental periods and therefore small perturbations can have important consequences. In addition, metabolic processing and elimination mechanisms are immature in the fetus and neonate, and so detoxification is inefficient (Beath 2003, Chen et al. 2006). Furthermore, many developmental processes are dependent on steroid hormones and secreted proteins whose activities have the potential to be altered by phytoestrogens based on the mechanisms of action outlined earlier. For example, testosterone secreted by the fetal testis is a key mediator of male gonad and reproductive tract development (Park \& Jameson 2005). Fetal exposure to estrogenic compounds can suppress testosterone synthesis, leading to cryptorchidism and adult testis dysfunction (Clark \& Cochrum 2007, Wohlfahrt-Veje et al. 2009). In addition, exposure to estrogenic chemicals during fetal life disrupts female reproductive tract development by altering the expression of genes encoding secreted signaling proteins critical for directing this process (Ma 2009); these effects have permanent consequences for reproductive tract morphology and function in both rodents and humans (Newbold et al. 2004, Baird \& Newbold 2005).

Although most organ systems in the fetus are highly sensitive to developmental insults, this sensitivity persists during postnatal life in several specific organ systems because they continue to develop after birth. For example, in humans, the brain continues to undergo significant growth and differentiation during the first several years of life, and there is evidence of continued brain development through late adolescence (reviewed in Sisk \& Zehr (2005)). Similarly, in animals including 
humans, the female reproductive tract is not completely differentiated at birth, but continues to undergo cellular differentiation until just before the onset of puberty (Valdes-Dapena 1973, Gray et al. 2001). Many of these postnatal differentiation events are dependent, at least in part, on steroid hormone signaling. For this reason, endocrine-disrupting chemicals, including phytoestrogens, could have a significant impact on postnatal development in ways that affect later reproductive health.

\section{Phytoestrogen exposure and reproductive health in animal models}

Reproductive health critically depends on proper sexually dimorphic fetal and postnatal development followed by sex-specific and coordinated functioning of the brain, gonads, reproductive tract, and external genitalia. Although other organ systems, particularly endocrine-related organs, also contribute to reproductive health, there is little information available regarding the impact of phytoestrogens on these other organs as they relate to reproductive function. For this reason, we limit the discussion that follows to the major organs and essential processes considered to be part of the reproductive system.

\section{Estrous cycle}

We have used a mouse model of neonatal exposure to the phytoestrogen genistein to study the impact of physiologically relevant levels of phytoestrogens on female reproductive health (Jefferson et al. 2005, $2009 b$ ). The initial dosing strategy achieved serum levels ranging from those observed in humans eating a nonvegetarian diet all the way to levels measured in infants fed soy-based infant formula as their major food source. Neonatal genistein treatment causes abnormal estrous cycles and anovulation as a result of abnormalities in the hypothalamic-pituitary-ovarian axis function (Jefferson et al. 2005). In the rat, neonatal genistein exposure alters pituitary sensitivity to a GNRH challenge, with a low genistein dose causing increased sensitivity and higher doses causing decreased sensitivity as indicated by LH release (Faber \& Hughes 1993). More recent work demonstrated that neonatal genistein alters hypothalamic kisspeptin signaling pathways and GNRH activity (Fig. 3; Losa et al. 2011). These pathways regulate both timing of pubertal onset and estrous cyclicity, and thus provide a likely explanation for the abnormal estrous cyclicity and anovulation observed in the mouse model. Based on studies in adult rats, resveratrol can also disrupt estrous cyclicity, although the underlying mechanism is not clear (Henry \& Witt 2002).

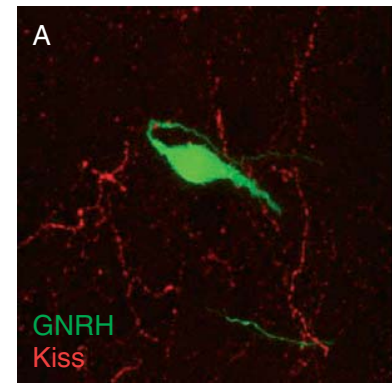

Control

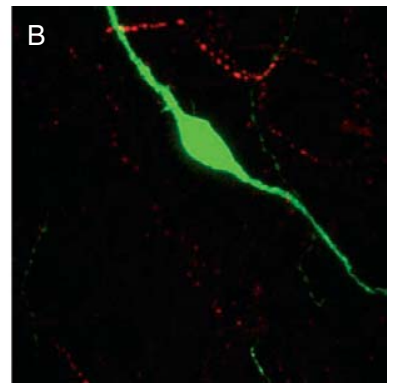

Genistein
Figure 3 Representative confocal images depicting the plexus of kisspeptin (Kiss) neuronal fibers surrounding GNRH neurons in the anterior hypothalamus. The density of Kiss projections is reduced by approximately half in postnatal day 28 female rats following neonatal exposure for 4 days to $10 \mathrm{mg} / \mathrm{kg}$ body weight genistein as described previously (Losa et al. 2011). A, control; B, genistein treated.

\section{Sexually dimorphic behavior}

Pre- and postnatally, the brain develops in a sexually dimorphic fashion that contributes to differential reproductive behaviors in response to hormonal stimuli during adulthood (Simerly 2002, Sakuma 2009, Roselli \& Stormshak 2010, Henley et al. 2011). For example, the sexually dimorphic nucleus of the preoptic area (SDN) is substantially larger in males than in females; in rams and rats, the size of this region is associated with sexual partner preference (Roselli \& Stormshak 2010, Henley et al. 2011). The SDN size difference is a result of exposure to testosterone, generated by the testis, and estradiol, which is generated in the brain by aromatization of testosterone. Indeed, testosterone and estradiol serve as the most important factors to establish permanent sex differences in brain organization during the fetal and neonatal periods (reviewed in Arnold (2009)). Although most sex differences are likely established during prenatal and neonatal development, it was shown recently in the rat that new cells are added to sexually dimorphic nuclei during adolescence in response to steroid hormone treatments (Ahmed et al. 2008), demonstrating the long-term sensitivity of sexually dimorphic brain regions to steroid hormone-mediated signaling.

Several phytoestrogens affect brain development and sexual behavior in animal models. For example, exposure of male rat pups to resveratrol via nursing is associated with smaller SDN size and reduced sociosexual behavior in adulthood (Henry \& Witt 2006). Coumestrol administration to neonatal female rats markedly reduced lordosis behavior in adulthood (Kouki et al. 2005). Finally, neonatal genistein exposure affected sexual behavior of adult male rats, an effect likely mediated by ER $\beta$ (Wisniewski et al. 2003, Sullivan et al. 2011). Notably, all these exposures occur during the neonatal period but affect adult behaviors, 
highlighting the importance of the timing of exposures in determining specific long-term outcomes.

\section{Testis function}

There is some evidence in animal models that developmental exposure to phytoestrogens affects testis function, but many studies found no effects, and so it is difficult to draw definitive conclusions (Cederroth et al. 2010). Several studies that did show alterations in testis function used long-term exposure protocols, beginning during gestation and continuing through adulthood. For example, two studies demonstrated that male rats chronically exposed to genistein had abnormalities in spermatogenesis (Delclos et al. 2001, Eustache et al. 2009). One of these studies also demonstrated that genistein caused alterations in sperm motility and a reduction in litter size accompanied by evidence of postimplantation embryo loss when the adult rats underwent fertility testing (Eustache et al. 2009). In a set of very nicely designed twin studies in marmosets, neonatal soy milk exposure was shown to alter testis cellular morphology and reduce serum testosterone levels when compared with the same parameters in twin siblings fed standard milk formula, but fertility was not different between the two groups (Sharpe et al. 2002, Tan et al. 2006).

\section{Ovarian function}

Female germ cells complete proliferation and begin meiosis prenatally and then arrest in meiosis I before or at the time of birth. Prenatal development is absolutely critical for female reproductive health because this is the last time that new daughter germ cells are generated. In rodents, primordial follicles form during the first postnatal week by the migration of pregranulosa cells to surround individual oocytes as oocyte nests break down. Exposure to genistein during this process causes failure of oocyte nest breakdown and leads to the development of multi-oocyte follicles (Chen et al. 2007, Cimafranca et al. 2010, Losa et al. 2011). It does not appear that the occurrence of multi-oocyte follicles impacts fertility; however, because embryos derived from neonatal genistein-treated mice are fully competent to develop to term if transferred into pseudopregnant control mice (Jefferson et al. 2009b).

\section{Female reproductive tract function}

In newborn rodents, the female reproductive tract is a simple bifurcated tube comprised of an outer epithelium, a muscle layer, a thin stromal layer, and a simple columnar epithelium. Extensive gross morphological and cellular differentiation begins in the immediate postnatal period and is complete by about postnatal day
15 in the mouse (Gray et al. 2001). This differentiation process is under the regulatory control of homeobox transcription factors, particularly the posterior Hoxa genes, and secreted signaling molecules that induce formation of the morphologically distinct reproductive tract regions: oviduct, uterus, cervix, and vagina (Ma 2009, Umezu et al. 2010). In addition to regional differentiation, the endometrial epithelium undergoes glandular morphogenesis postnatally to form branched glandular structures in the endometrial stroma. These cellular and regional differentiation processes are exquisitely sensitive to disruption by steroid hormone signaling (Gray et al. 2001).

Phytoestrogens dramatically alter development of the rodent female reproductive tract. Neonatal genistein exposure disrupts oviductal morphogenesis by altering hedgehog signaling pathways and expression of homeobox genes and other transcription factors (Jefferson et al. 2011). As a result, the oviduct becomes 'posteriorized', i.e. expresses genes and proteins normally observed only in posterior regions of the reproductive tract (cervix and vagina) (Fig. 4). The abnormally expressed genes include several developmentally important homeobox transcription factors that are absent in control oviducts, including Pitx 1 and Six1 (Jefferson et al. 2011). In addition, microarray analysis of oviduct gene expression on pregnancy day 2 revealed that neonatal genistein exposure causes significant alterations in gene expression in the category of inflammatory response pathways, many of which are hormonally regulated. This suggests the presence of alterations in oviductal mucosal immune responses during early pregnancy that could impact embryo survival and development (Jefferson et al. 2011).

There is a wealth of information available regarding the effects of developmental exposure to phytoestrogens on uterine morphology and function. For example, treatment of immature rats for 1 week with resveratrol increased uterine wet weight and glandular morphogenesis (Singh et al. 2011). These changes were accompanied by alterations in several endometrial prosurvival or antiapoptotic factors, but whether resveratrol treatment at this time in development has permanent effects is unknown. Treatment of neonatal rats with coumestrol caused early vaginal opening and an initial increase in uterine wet weight during the time of treatment followed by a later decrease in adult uterine weight (Medlock et al. 1994, Losa et al. 2011). This was also true for mice treated neonatally with DES (Newbold et al. 2004). When coumestrol was administered to rats slightly later, during postnatal days 10-14 that are critical for glandular morphogenesis, fewer endometrial glands were observed in the adults and ER expression was reduced (Medlock et al. 1994, 1995a). Mice treated neonatally with coumestrol developed squamous metaplasia and had abnormal collagen deposition in the uterine wall by 22 months of age 


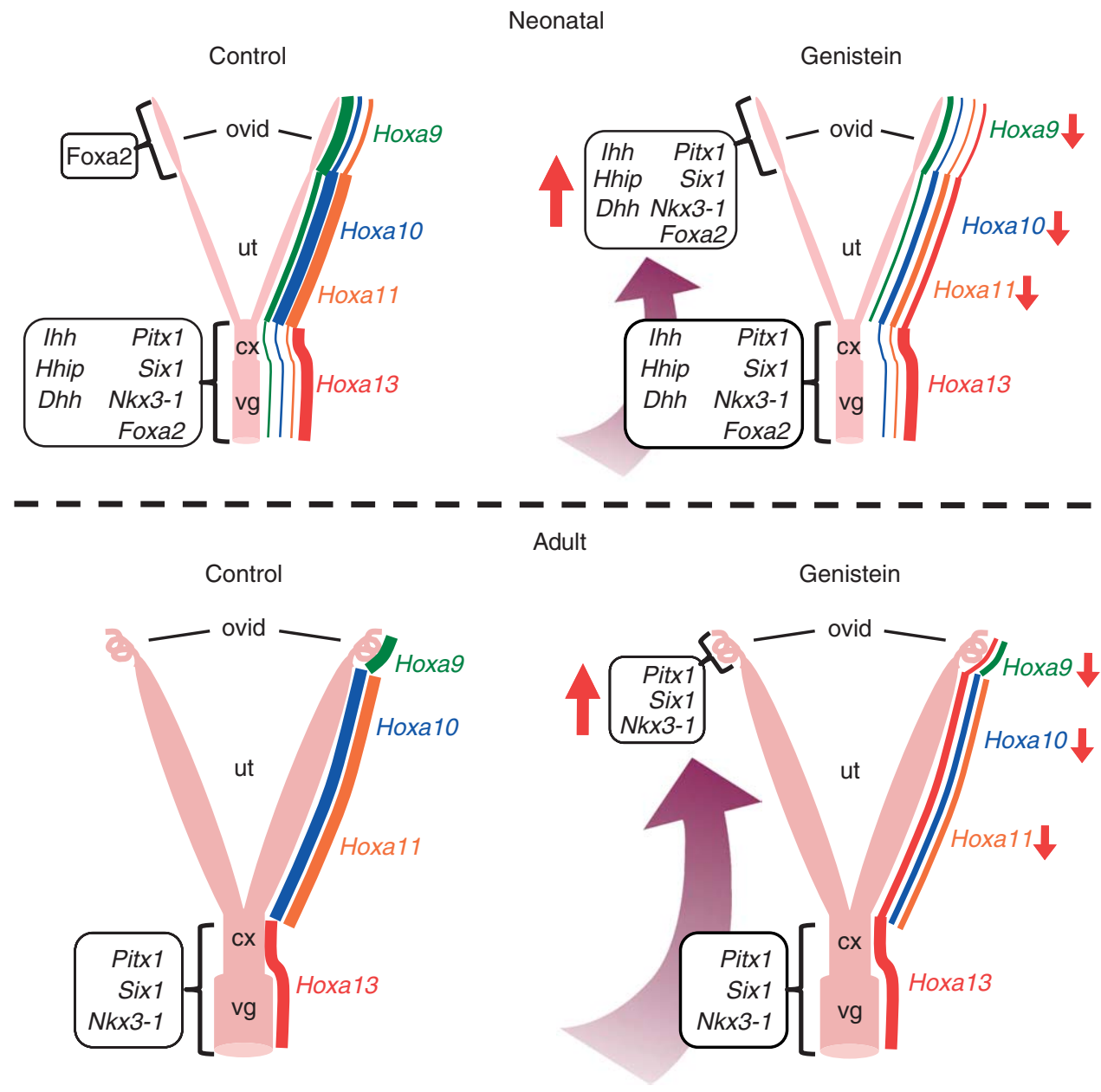

Figure 4 Schematic representation of posteriorization of the female reproductive tract after neonatal genistein exposure. Upper panels: neonatal genistein exposure alters expression of Hoxa genes along the anterior-posterior axis of the postnatal day 5 uterus. In addition, hedgehog family secreted signaling factors and other transcription factors normally expressed in the cervix and vagina are abnormally expressed in the oviduct after 5 days of genistein treatment. Lower panels: alterations in expression of Hoxa genes and other transcription factors persist in the adult female reproductive tract following neonatal genistein exposure. Hoxa gene expression depicted on the right side of each schematic; line thickness and font size indicate relative expression levels. Expression of other genes indicated in boxes to the left side of each schematic; font size and direction of red arrows indicate relative expression levels compared with controls. Ovid, oviduct; Ut, uterus; Cx, cervix; Vg, vagina. Information presented is from Jefferson et al. (2011).

(Burroughs et al. 1990a). Together, these studies overwhelmingly support the concept that brief exposure to phytoestrogens during the developmentally sensitive periods can have permanent effects on uterine morphology and function.

Although we are mainly focusing here on reproductive outcomes, developmental phytoestrogen exposure is also associated with uterine carcinogenesis. Indeed, mice treated neonatally with genistein had a 35\% incidence of uterine cancer by 18 months of age (Newbold et al. 2001). This incidence is similar to the incidence seen when mice are given an equally estrogenic dose of DES, suggesting that it is mediated by ER signaling. Of note, the cancer phenotype is not observed if the DES-exposed mice are ovariectomized before puberty, indicating that a 'second hit' of steroid hormone exposure is required (Newbold et al. 1990). In contrast, a recent study demonstrated the beneficial effects of neonatal exposure to phytoestrogens on uterine carcinogenesis (Begum et al. 2006). This study used mice heterozygous for a knockout allele of the tumor suppressor phosphatase and tensin homolog (Pten) that have a very high incidence of endometrial hyperplasia and adenocarcinoma by 12 months of age. Neonatal exposure to genistein at the same doses used by Newbold et al. (2001) strongly suppressed endometrial carcinogenesis in the Pten ${ }^{+/-}$model. Of note, the genistein-exposed Pten ${ }^{+/-}$mice demonstrated alterations in endometrial stromal morphology and reductions in expression of Hoxa10 and Hoxa11 similar to those we had observed after treating wild-type mice with genistein (W N J and C J W, unpublished observations), suggesting 
that the different outcome was related to differences in cancer etiology in the two models and not differences in genistein effects.

The mechanisms underlying the persistence of altered uterine phenotypes into adulthood after these developmental exposures, and in the case of neonatal DESexposed mice, transmission to subsequent generations (Newbold et al. 1998, 2000), are not known and are active areas of current research. The most likely explanation is that endocrine disruption during development results in permanent epigenetic changes responsible for the abnormal phenotype that are maintained into adulthood and can be stably transmitted to the next generation. There are precedents for the epigenetic changes occurring after developmental exposure to endocrine disruptors including phytoestrogens and other environmental cues (Wade \& Archer 2006, Jirtle \& Skinner 2007, Jones \& Baylin 2007). These exposures can alter the DNA methylation status of specific genes ( $\mathrm{Li}$ et al. 2007, Tang et al. 2008) or alter methylation patterns on a more global scale (Anway et al. 2005, Dolinoy et al. 2007), suggesting that methylation is one potential mechanism for this phenomenon. Indeed, there is some evidence in mice that prenatal DES exposure can increase methylation of Hoxa10, a gene important for uterine development and adult uterine function (Bromer et al. 2009). However, the functional significance of these methylation changes is not known, and similar alterations in Hoxa10 methylation were not observed after prenatal genistein or daidzein exposure (Akbas et al. 2007). A recent study demonstrated that exposure of ovariectomized adult rats to high doses of genistein caused subtle decreases in methylation of the steroidogenic factor 1 promoter associated with increased expression of this gene in the endometrium, but whether the protein level was altered and whether the effects were permanent is unknown (Matsukura et al. 2011). We anticipate that future studies that could examine a more complete scope of epigenetic alterations such as histone modifications and alterations in three-dimensional chromatin structure will help to shed light on the mechanistic basis of the permanent reproductive tract alterations observed after developmental phytoestrogen exposure.

\section{Reproductive tract influence on embryo development in the mouse}

It should come as no surprise that abnormalities in reproductive tract development can result in alterations in embryo development. Adult females treated neonatally with genistein occasionally ovulate spontaneously up to about 8 weeks of age, but after that time remain in a state of persistent estrous and are anovulatory (Jefferson et al. 2005). They can, however, be superovulated with gonadotropins and then bred to fertile males. These mice achieve pregnancy, but fertilization is delayed by several hours when compared with controls (Jefferson et al. 2009b).
If the pronuclear-stage embryos are removed from the oviduct and cultured in vitro, they develop normally to the blastocyst stage and can develop to term if transferred into control pseudopregnant females. If left in the oviduct, however, by the third day of pregnancy, about half of the embryos are reabsorbed (Fig. 5). The surviving embryos develop in vivo at a faster rate than in the case of controls and have an altered trophectoderm: inner cell mass ratio ( $\mathrm{W} \mathrm{N} \mathrm{J} \mathrm{and} \mathrm{C} J \mathrm{~W}$, unpublished observations). Some of the embryos that survive transit through the oviduct implant in the uterus, but the implantation sites are abnormal and the embryos do not develop to term (Jefferson et al. 2005). This is not a consequence of an abnormal steroid hormone milieu because the serum levels of estrogen, progesterone, and testosterone in these mice are within the normal range on days 6, 8, and 10 of pregnancy (Jefferson et al. 2005). Instead, the uterus is not competent to support embryo development, even if blastocysts from untreated control mice are transferred into pseudopregnant genisteintreated mice (Jefferson et al. 2009b). These findings demonstrate that neonatal phytoestrogen exposure alters female reproductive tract development in ways that can directly affect the development of the subsequent generation of embryos.
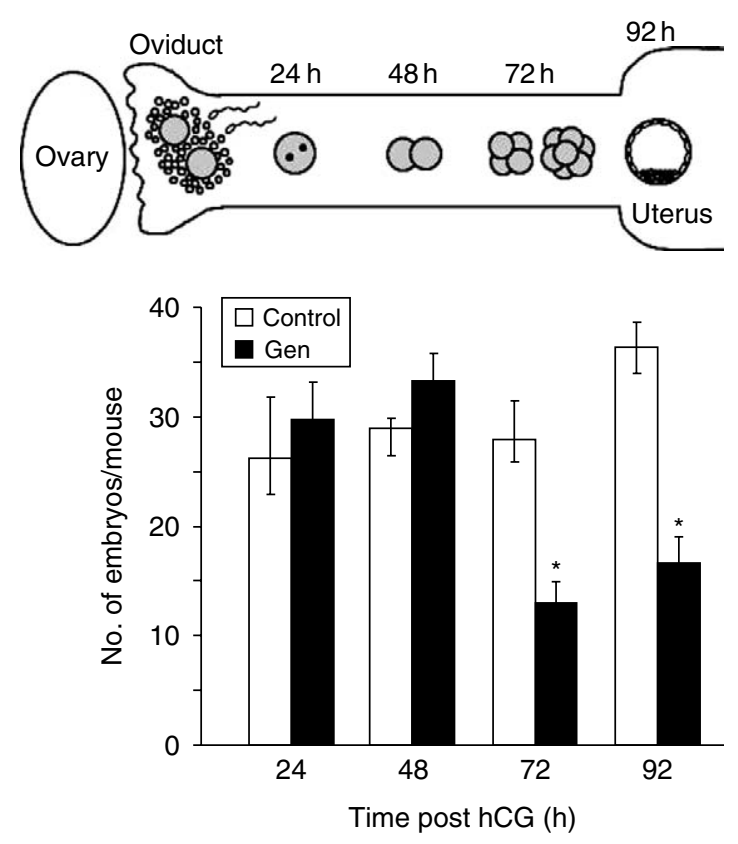

Figure 5 Embryo loss during transit through the oviduct in adult mice treated neonatally with genistein. Embryos were flushed from the oviduct and uterus of control (white bars) and neonatal genisteintreated (black bars) superovulated mice at the indicated times after human chorionic gonadotropin (hCG) administration and mating. Graph shows mean number \pm s.E.M. of embryos per mouse. $* P<0.05$ compared to control at the same time point. Schematic above the graph indicates expected embryo stage and location within the female reproductive tract at the different time points. Modified from Jefferson et al. $(2009 b)$. 


\section{External genitalia}

Male differentiation of the external genitalia occurs prenatally in response to testosterone produced by the fetal testis and dihydrotestosterone generated locally in external genital tissues (Park \& Jameson 2005). Several studies have demonstrated the effects of phytoestrogens on external genital development or function in rodents. Gestational and/or lactational genistein exposure can cause a reduction in anogenital distance in male mice and rats (Levy et al. 1995, Wisniewski et al. 2003, 2005, Ball et al. 2010). One study demonstrated that erectile function is abnormal in juvenile rats exposed to daidzein for 3 months (Pan et al. 2008). Finally, hypospadias was observed in $25 \%$ of male mice exposed prenatally to genistein (Vilela et al. 2007). This finding is likely explained by genistein-mediated alterations in the expression of genes important for urethral morphogenesis including some regulated by ER signaling (Ross et al. 2011).

In the absence of prenatal androgen exposure, female external genitalia will form. Completion of female mouse external genitalia development is delayed in comparison with males because at birth there is incomplete fusion of the urethral folds. Urethral fold fusion is not complete until after postnatal day 5 and is sensitive to disruption by estrogenic chemicals in the neonatal period (Miyagawa et al. 2002). We recently demonstrated that female mice exposed neonatally to genistein have a $100 \%$ incidence of hypospadias (Padilla-Banks et al. 2011). As in males, exposure of female rats during gestation to phytoestrogens including genistein and lignans can cause reduced anogenital distance (Tou et al. 1998, Delclos et al. 2009).

\section{Phytoestrogen exposure and reproductive health in humans}

Although work in animal model systems suggests that phytoestrogens impact reproductive health, we next consider evidence in humans that this might be the case. Human studies on this topic are difficult to carry out given their typical complexity and dependence on relatively long-term observational studies rather than the treatment-based outcomes measured in animal models. Nevertheless, several studies have been published regarding the effects of developmental phytoestrogen exposure on the brain, reproductive tract, and external genitalia that are relevant to human reproduction.

\section{Sexually dimorphic behavior}

Studies in animal models have indicated that many of the effects of androgens on behavior are mediated by activation of ER-based signaling, presumably by aromatization of androgens to generate estrogen within the brain (Wu \& Shah 2011). It is well established in humans that prenatal exposure to androgens can result in masculinization of behavior (Hines 2008). There is much less information available regarding the effects of estrogens or phytoestrogens on sexually dimorphic behavior in humans. However, a longitudinal study examining the impact of human infant exposure to soybased formula on gender-role- play behavior was recently published (Adgent et al. 2011b). This study of over 7000 children enrolled in the Avon Longitudinal Study of Parents and Children (ALSPAC) found an association between early-life soy exposure (starting before age 4 months) and masculinized play behavior in girls at age 42 months. There were no measurable effects in boys, and the effects on girls were attenuated by 57 months of age. The consistency of these findings with behavioral changes observed in well-controlled studies using animal models suggest that evidence obtained from animal studies regarding the effects of exposure to estrogenic chemicals in early life on adult reproductive behavior is relevant to behavioral outcomes in humans.

\section{Puberty}

The timing of pubertal onset is a result of complex interactions between endocrine system organs including the brain, gonads, and adipose tissue that depend on peptide and steroid hormone actions, and as such could be affected by early-life phytoestrogen exposure. A subset of girls in the ALSPAC cohort described earlier who provided information regarding pubertal timing $(n=2920)$ was used to examine associations between early-life soy exposure and timing of menarche (Adgent et al. 2011a). The early-soy-exposure group had a $25 \%$ increased risk of menarche before age 12 when compared with girls fed other types of infant formula or milk. However, the study was limited by the fact that only $2 \%$ of the subjects had early soy exposure, and loss to follow-up was significant.

A recent case-control study of $\sim 200$ Korean girls aged 8-10 years demonstrated that high serum isoflavone levels (daidzein and genistein) are associated with central precocious puberty (Kim et al. 2011). Central precocious puberty was diagnosed using strict criteria of breast budding before age 8 , bone age advanced more than 1 year, and a positive GNRH stimulation test. In fact, there was about a fourfold increased risk of central precocious puberty in girls who had total isoflavone levels in the middle (30-70 $\mathrm{nM})$ or high $(\geq 70 \mathrm{nM})$ range compared with the lowest range $(<30 \mathrm{nM})$. This study is in contrast to two observational studies of the timing of pubertal onset that demonstrated an association of higher urinary isoflavone levels with slightly later onset of breast development (Wolff et al. 2008, Cheng et al. 2010). One of these studies was in an ethnically mixed population of 9-year-old girls in New York City and the other used a prospectively followed cohort of children in 
Germany. A multicenter prospective longitudinal study of over 1100 girls in the USA found essentially no association between urinary phytoestrogen levels and onset of breast development (Wolff et al. 2008). Although there were many methodological differences between the studies, one interpretation of the slightly conflicting results is that phytoestrogen exposure early in the prepubertal period when endogenous estradiol levels are low could predispose girls to central precocious puberty, whereas later phytoestrogen exposure could serve to interfere with endogenous estrogen-mediated stimulation of breast development because of weak ER agonist activity.

\section{Female reproductive tract}

The consequences of exposing pregnant women to DES made clear the potential impact of estrogenic chemicals on female reproductive tract development in humans. In addition to the increased incidence of vaginal cancer in daughters of DES-treated women, there is also a high incidence of female reproductive tract malformations that are associated with ectopic pregnancy and premature delivery and an increased incidence of uterine fibroids (Stillman 1982, Baird \& Newbold 2005). The DES experience also demonstrated the critical importance of timing and dose of exposure to estrogenic chemicals in determining the extent of abnormalities in human female reproductive tract development, with a higher incidence and higher severity of abnormalities after earlier exposure to higher doses (Jefferies et al. 1984).

To date, only two studies have examined the relationship between phytoestrogen exposure and adult female reproductive tract function; in these studies, the exposure was postnatal. One small retrospective study found that women fed soy formula as infants reported longer menstrual bleeding and more dysmenorrhea than women who were not exposed to soy formula (Strom et al. 2001). The second study, which included almost 20000 women, linked use of soy formula during infancy with a slightly increased risk of early diagnosis of uterine fibroids (D'Aloisio et al. 2010). Although fibroids have not been reported following neonatal phytoestrogen exposure in animal models, these findings are consistent with the observations that rats and humans exposed to DES during developmental periods have an increased incidence of uterine fibroids as adults (Baird \& Newbold 2005, Cook et al. 2007).

\section{Male reproductive tract}

Male fetuses also have adverse effects of developmental exposure to estrogenic chemicals that affect their ability to reproduce. A collaborative cohort study of about 1200 sons of DES-treated women demonstrated an increased incidence of cryptorchidism, epididymal cysts, and inflammation or infection of the testis, particularly when exposure occurred before gestational week 11 (Palmer et al. 2009). These findings are consistent with the reported effects of estradiol in inhibiting insulin-like 3 -mediated signaling that is required for testicular descent and estradiol-mediated inhibition of antiMüllerian hormone activity that is important for Müllerian duct regression (Visser et al. 1998, Cederroth et al. 2007). There are conflicting results in the literature regarding whether DES-exposed males have an increased risk of hypospadias, with several studies indicating an increased risk but other studies not replicating this finding (Brouwers et al. 2010). There is a single report of an approximately fivefold increased risk of hypospadias in sons of mothers who ate a vegetarian diet during pregnancy (North \& Golding 2000). Whether this finding is due to phytoestrogen exposure or whether it is caused by concomitant ingestion of other chemicals, e.g. pesticides, that could be more prevalent in a vegetarian diet, is unknown. However, a mouse study regarding the effects of genistein alone or combined with the pesticide vinclozolin suggests that both chemicals can increase the incidence of hypospadias (Vilela et al. 2007).

\section{Summary}

There is overwhelming evidence in animal models that phytoestrogen exposure can have significant consequences for reproductive health. The effects observed depend on the dose and route of exposure because these parameters impact the final serum level of the bioactive compound. In addition, the timing of exposure is critical in determining phenotypic effects because different tissues have species-specific windows of sensitivity to morphological and functional disruption. These sensitive windows generally begin in the early prenatal period and extend in some cases through adulthood. As more phytoestrogens are recognized or developed as therapeutic compounds, it will be important to examine carefully the effects of these chemicals on reproductive outcomes using animal models that replicate human exposure levels.

Although the effects of phytoestrogens have been evaluated in only a small number of human studies, several of these studies are consistent with findings in animal models after taking into consideration the different developmental timing of specific tissues. Other human studies are more difficult to interpret because of inherent weaknesses in study designs involving large populations of human subjects, difficulties in quantifying phytoestrogen exposures, and an inability to fully control unknown factors in the diet or from the environment that could influence outcomes. There is a need for additional well-designed prospective human studies that limit these variables as much as 
possible and focus on environmentally relevant levels of phytoestrogen exposure. Despite their limitations, information gathered from the published human studies combined with the large number of animal studies already available clearly demonstrates that phytoestrogens have the ability to permanently reprogram adult tissue responses after a developmental exposure and that these altered tissue responses are important for reproductive health. These findings should be taken into account when recommendations are made regarding dietary or therapeutic phytoestrogen intake, while keeping in mind the developmentally sensitive time points.

\section{Declaration of interest}

The authors declare that there is no conflict of interest that could be perceived as prejudicing the impartiality of the research reported.

\section{Funding}

This work was supported by the Intramural Research Program of the NIH, National Institutes of Environmental Health Sciences (Z01-ES102405, C J Williams) and by the NIH, National Institutes of Environmental Health Sciences (R01ES016001, H B Patisaul).

\section{Acknowledgements}

We thank Walter Rogan and Humphrey Yao (NIEHS) for critical review of the manuscript and Lois Wyrick (NIEHS) for assistance with artwork.

\section{References}

Adgent M, Daniels J, Rogan W, Adair L, Edwards L, Westreich D, Maisonet M \& Marcus M 2011a Early life soy exposure and age at menarche. Paediatric and Perinatal Epidemiology [in press]. (doi:10. 1111/j.1365-3016.2011.01244.x)

Adgent M, Daniels JL, Edwards L, Siega-Riz AM \& Rogan WJ 2011b Early life soy exposure and gender-role play behavior in children. Environmental Health Perspectives 119 1811-1816. (doi:10.1289/ehp. 1103579)

Adlercreutz H, Fotsis T, Watanabe S, Lampe J, Wahala K, Makela T \& Hase T 1994 Determination of lignans and isoflavonoids in plasma by isotope dilution gas chromatography-mass spectrometry. Cancer Detection and Prevention 18 259-271.

Ahmed El, Zehr JL, Schulz KM, Lorenz BH, DonCarlos LL \& Sisk CL 2008 Pubertal hormones modulate the addition of new cells to sexually dimorphic brain regions. Nature Neuroscience 11 995-997. (doi:10. 1038/nn.2178)

Akbas GE, Fei X \& Taylor HS 2007 Regulation of HOXA10 expression by phytoestrogens. American Journal of Physiology. Endocrinology and Metabolism 292 E435-E442. (doi:10.1152/ajpendo.00167.2006)

Amsterdam A, Abu-Rustum N, Carter J \& Krychman M 2005 Persistent sexual arousal syndrome associated with increased soy intake. Journal of Sexual Medicine 2 338-340. (doi:10.1111/j.1743-6109.2005.20358.x)

Anway MD, Cupp AS, Uzumcu M \& Skinner MK 2005 Epigenetic transgenerational actions of endocrine disruptors and male fertility. Science 308 1466-1469. (doi:10.1126/science.1108190)
Arnold AP 2009 The organizational-activational hypothesis as the foundation for a unified theory of sexual differentiation of all mammalian tissues. Hormones and Behavior 55 570-578. (doi:10.1016/j.yhbeh. 2009.03.011)

Baird DD \& Newbold R 2005 Prenatal diethylstilbestrol (DES) exposure is associated with uterine leiomyoma development. Reproductive Toxicology 20 81-84. (doi:10.1016/j.reprotox.2005.01.002)

Ball ER, Caniglia MK, Wilcox JL, Overton KA, Burr MJ, Wolfe BD, Sanders BJ, Wisniewski AB \& Wrenn CC 2010 Effects of genistein in the maternal diet on reproductive development and spatial learning in male rats. Hormones and Behavior 57 313-322. (doi:10.1016/j.yhbeh.2009. 12.013)

Bateman HL \& Patisaul HB 2008 Disrupted female reproductive physiology following neonatal exposure to phytoestrogens or estrogen specific ligands is associated with decreased GnRH activation and kisspeptin fiber density in the hypothalamus. Neurotoxicology 29 988-997. (doi:10.1016/j.neuro.2008.06.008)

Beath SV 2003 Hepatic function and physiology in the newborn. Seminars in Neonatology 8 337-346. (doi:10.1016/S1084-2756(03)00066-6)

Begum M, Tashiro H, Katabuchi H, Suzuki A, Kurman RJ \& Okamura H 2006 Neonatal estrogenic exposure suppresses PTEN-related endometrial carcinogenesis in recombinant mice. Laboratory Investigation $\mathbf{8 6}$ 286-296. (doi:10.1038/labinvest.3700380)

Bennetts HW, Underwood EJ \& Shier FL 1946 A specific breeding problem of sheep on subterranean clover pastures in Western Australia. Australian Veterinary Journal 22 2-12. (doi:10.1111/j.1751-0813.1946. tb15473.x)

Bernbaum JC, Umbach DM, Ragan NB, Ballard JL, Archer JI, SchmidtDavis H \& Rogan WJ 2008 Pilot studies of estrogen-related physical findings in infants. Environmental Health Perspectives 116 416-420. (doi:10.1289/ehp.10409)

Bromer JG, Wu J, Zhou Y \& Taylor HS 2009 Hypermethylation of homeobox A10 by in utero diethylstilbestrol exposure: an epigenetic mechanism for altered developmental programming. Endocrinology 150 3376-3382. (doi:10.1210/en.2009-0071)

Brouwers MM, van der Zanden LF, de Gier RP, Barten EJ, Zielhuis GA, Feitz WF \& Roeleveld N 2010 Hypospadias: risk factor patterns and different phenotypes. BJU International 105 254-262. (doi:10.1111/j. 1464-410X.2009.08772.x)

Burroughs CD, Mills KT \& Bern HA 1990a Long-term genital tract changes in female mice treated neonatally with coumestrol. Reproductive Toxicology 4 127-135. (doi:10.1016/0890-6238(90)90007-I)

Burroughs CD, Mills KT \& Bern HA $1990 b$ Reproductive abnormalities in female mice exposed neonatally to various doses of coumestrol. Journal of Toxicology and Environmental Health 30 105-122. (doi:10. 1080/15287399009531415)

Cao Y, Calafat AM, Doerge DR, Umbach DM, Bernbaum JC, Twaddle NC, Ye X \& Rogan WJ 2009 Isoflavones in urine, saliva, and blood of infants: data from a pilot study on the estrogenic activity of soy formula. Journal of Exposure Science and Environmental Epidemiology 19 223-234. (doi:10.1038/jes.2008.44)

Cederroth CR, Schaad O, Descombes P, Chambon P, Vassalli JD \& Nef S 2007 Estrogen receptor $\alpha$ is a major contributor to estrogen-mediated fetal testis dysgenesis and cryptorchidism. Endocrinology $\mathbf{1 4 8}$ 5507-5519. (doi:10.1210/en.2007-0689)

Cederroth CR, Auger J, Zimmermann C, Eustache F \& Nef S 2010 Soy, phyto-oestrogens and male reproductive function: a review. International Journal of Andrology 33 304-316. (doi:10.1111/j.1365-2605.2009. 01011.x)

Chandrareddy A, Muneyyirci-Delale O, McFarlane SI \& Murad OM 2008 Adverse effects of phytoestrogens on reproductive health: a report of three cases. Complementary Therapies in Clinical Practice 14 132-135. (doi:10.1016/j.ctcp.2008.01.002)

Chen N, Aleksa K, Woodland C, Rieder M \& Koren G 2006 Ontogeny of drug elimination by the human kidney. Pediatric Nephrology 21 160-168. (doi:10.1007/s00467-005-2105-4)

Chen Y, Jefferson WN, Newbold RR, Padilla-Banks E \& Pepling ME 2007 Estradiol, progesterone, and genistein inhibit oocyte nest breakdown and primordial follicle assembly in the neonatal mouse ovary in vitro and in vivo. Endocrinology 148 3580-3590. (doi:10.1210/en. 2007-0088) 
Cheng G, Remer T, Prinz-Langenohl R, Blaszkewicz M, Degen GH \& Buyken AE 2010 Relation of isoflavones and fiber intake in childhood to the timing of puberty. American Journal of Clinical Nutrition 92 556-564. (doi:10.3945/ajcn.2010.29394)

Cimafranca MA, Davila J, Ekman GC, Andrews RN, Neese SL, Peretz J, Woodling KA, Helferich WG, Sarkar J, Flaws JA et al. 2010 Acute and chronic effects of oral genistein administration in neonatal mice. Biology of Reproduction 83 114-121. (doi:10.1095/biolreprod.109.080549)

Clark BJ \& Cochrum RK 2007 The steroidogenic acute regulatory protein as a target of endocrine disruption in male reproduction. Drug Metabolism Reviews 39 353-370. (doi:10.1080/03602530701519151)

Cook JD, Davis BJ, Goewey JA, Berry TD \& Walker CL 2007 Identification of a sensitive period for developmental programming that increases risk for uterine leiomyoma in Eker rats. Reproductive Sciences 14 121-136. (doi:10.1177/1933719106298401)

de Cremoux P, This P, Leclercq G \& Jacquot Y 2010 Controversies concerning the use of phytoestrogens in menopause management: bioavailability and metabolism. Maturitas 65 334-339. (doi:10.1016/j. maturitas.2009.12.019)

D'Aloisio AA, Baird DD, DeRoo LA \& Sandler DP 2010 Association of intrauterine and early-life exposures with diagnosis of uterine leiomyomata by 35 years of age in the Sister Study. Environmental Health Perspectives 118 375-381. (doi:10.1289/ehp.0901423)

Dang ZC 2009 Dose-dependent effects of soy phyto-oestrogen genistein on adipocytes: mechanisms of action. Obesity Reviews 10 342-349. (doi:10.1111/j.1467-789X.2008.00554.x)

Delclos KB, Bucci TJ, Lomax LG, Latendresse JR, Warbritton A, Weis CC \& Newbold RR 2001 Effects of dietary genistein exposure during development on male and female CD (Sprague-Dawley) rats. Reproductive Toxicology 15 647-663. (doi:10.1016/S0890-6238(01)00177-0)

Delclos KB, Weis CC, Bucci TJ, Olson G, Mellick P, Sadovova N, Latendresse JR, Thorn B \& Newbold RR 2009 Overlapping but distinct effects of genistein and ethinyl estradiol $(\operatorname{EE}(2))$ in female SpragueDawley rats in multigenerational reproductive and chronic toxicity studies. Reproductive Toxicology 27 117-132. (doi:10.1016/j.reprotox. 2008.12.005)

Diel P, Schulz T, Smolnikar K, Strunck E, Vollmer G \& Michna H 2000 Ability of xeno- and phytoestrogens to modulate expression of estrogensensitive genes in rat uterus: estrogenicity profiles and uterotropic activity. Journal of Steroid Biochemistry and Molecular Biology 73 1-10. (doi:10.1016/S0960-0760(00)00051-0)

Doerge DR, Twaddle NC, Banks EP, Jefferson WN \& Newbold RR 2002 Pharmacokinetic analysis in serum of genistein administered subcutaneously to neonatal mice. Cancer Letters 184 21-27. (doi:10.1016/ s0304-3835(02)00200-8)

Dolinoy DC, Huang D \& Jirtle RL 2007 Maternal nutrient supplementation counteracts bisphenol A-induced DNA hypomethylation in early development. PNAS 104 13056-13061. (doi:10.1073/pnas.07037 39104)

Eustache F, Mondon F, Canivenc-Lavier MC, Lesaffre C, Fulla Y, Berges R, Cravedi JP, Vaiman D \& Auger J 2009 Chronic dietary exposure to a lowdose mixture of genistein and vinclozolin modifies the reproductive axis, testis transcriptome, and fertility. Environmental Health Perspectives 117 1272-1279. (doi:10.1289/ehp.0800158)

Faber KA \& Hughes CL Jr 1993 Dose-response characteristics of neonatal exposure to genistein on pituitary responsiveness to gonadotropin releasing hormone and volume of the sexually dimorphic nucleus of the preoptic area (SDN-POA) in postpubertal castrated female rats. Reproductive Toxicology 7 35-39. (doi:10.1016/ 0890-6238(93)90007-T)

Foster WG, Chan S, Platt L \& Hughes CL Jr 2002 Detection of phytoestrogens in samples of second trimester human amniotic fluid. Toxicology Letters 129 199-205. (doi:10.1016/S03784274(02)00018-8)

Franke AA, Custer LJ, Wang W \& Shi CY 1998 HPLC analysis of isoflavonoids and other phenolic agents from foods and from human fluids. Proceedings of the Society for Experimental Biological Medicine 217 263-273.

Gray CA, Bartol FF, Tarleton BJ, Wiley AA, Johnson GA, Bazer FW \& Spencer TE 2001 Developmental biology of uterine glands. Biology of Reproduction 65 1311-1323. (doi:10.1095/biolreprod65.5.1311)
Henley CL, Nunez AA \& Clemens LG 2011 Hormones of choice: the neuroendocrinology of partner preference in animals. Frontiers in Neuroendocrinology 32 146-154. (doi:10.1016/j.yfrne.2011.02.010)

Henry LA \& Witt DM 2002 Resveratrol: phytoestrogen effects on reproductive physiology and behavior in female rats. Hormones and Behavior 41 220-228. (doi:10.1006/hbeh.2001.1754)

Henry LA \& Witt DM 2006 Effects of neonatal resveratrol exposure on adult male and female reproductive physiology and behavior. Developmental Neuroscience 28 186-195. (doi:10.1159/000091916)

Hines M 2008 Early androgen influences on human neural and behavioural development. Early Human Development 84 805-807. (doi:10.1016/j. earlhumdev.2008.09.006)

Jefferies JA, Robboy SJ, O'Brien PC, Bergstralh EJ, Labarthe DR, Barnes AB, Noller KL, Hatab PA, Kaufman RH \& Townsend DE 1984 Structural anomalies of the cervix and vagina in women enrolled in the Diethylstilbestrol Adenosis (DESAD) Project. American Journal of Obstetrics and Gynecology 148 59-66.

Jefferson WN, Padilla-Banks E, Clark G \& Newbold RR 2002 Assessing estrogenic activity of phytochemicals using transcriptional activation and immature mouse uterotrophic responses. Journal of Chromatography. $B$, Analytical Technologies in the Biomedical and Life Sciences 777 179-189. (doi:10.1016/S1570-0232(02)00493-2)

Jefferson WN, Padilla-Banks E \& Newbold RR 2005 Adverse effects on female development and reproduction in CD-1 mice following neonatal exposure to the phytoestrogen genistein at environmentally relevant doses. Biology of Reproduction 73 798-806. (doi:10.1095/biolreprod. 105.041277)

Jefferson WN, Doerge D, Padilla-Banks E, Woodling KA, Kissling GE \& Newbold R 2009a Oral exposure to genistin, the glycosylated form of genistein, during neonatal life adversely affects the female reproductive system. Environmental Health Perspectives 117 1883-1889.

Jefferson WN, Padilla-Banks E, Goulding EH, Lao SP, Newbold RR \& Williams CJ $2009 b$ Neonatal exposure to genistein disrupts ability of female mouse reproductive tract to support preimplantation embryo development and implantation. Biology of Reproduction 80 425-431. (doi:10.1095/biolreprod.108.073171)

Jefferson WN, Padilla-Banks E, Phelps JY, Gerrish KE \& Williams CJ 2011 Permanent oviduct posteriorization following neonatal exposure to the phytoestrogen genistein. Environmental Health Perspectives 119 1575-1582. (doi:10.1289/ehp.1104018)

Jirtle RL \& Skinner MK 2007 Environmental epigenomics and disease susceptibility. Nature Reviews. Genetics 8 253-262. (doi:10.1038/ nrg2045)

Jones PA \& Baylin SB 2007 The epigenomics of cancer. Cell 128 683-692. (doi:10.1016/j.cell.2007.01.029)

Kallela K, Heinonen K \& Saloniemi H 1984 Plant oestrogens; the cause of decreased fertility in cows. A case report. Nordisk Veterinaermedicin 36 124-129.

Kao YC, Zhou C, Sherman M, Laughton CA \& Chen S 1998 Molecular basis of the inhibition of human aromatase (estrogen synthetase) by flavone and isoflavone phytoestrogens: a site-directed mutagenesis study. Environmental Health Perspectives 106 85-92. (doi:10.1289/ehp. 9810685)

Keel BA, Eddy KB, Cho S, Gangrade BK \& May JV 1992 Purified human $\alpha$ fetoprotein inhibits growth factor-stimulated estradiol production by porcine granulosa cells in monolayer culture. Endocrinology 130 3715-3717. (doi:10.1210/en.130.6.3715)

Kim J, Kim SH, Huh K, Kim Y, Joung H \& Park MJ 2011 High serum isoflavone concentrations are associated with the risk of precocious puberty in Korean girls. Clinical Endocrinology 75 831-835. (doi:10. 1111/j.1365-2265.2011.04127.x)

Korach KS \& McLachlan JA 1985 The role of the estrogen receptor in diethylstilbestrol toxicity. Archives of Toxicology. Supplement $833-42$.

Kouki T, Kishitake M, Okamoto M, Oosuka I, Takebe M \& Yamanouchi K 2003 Effects of neonatal treatment with phytoestrogens, genistein and daidzein, on sex difference in female rat brain function: estrous cycle and lordosis. Hormones and Behavior 44 140-145. (doi:10.1016/S0018506X(03)00122-3)

Kouki T, Okamoto M, Wada S, Kishitake M \& Yamanouchi K 2005 Suppressive effect of neonatal treatment with a phytoestrogen, coumestrol, on lordosis and estrous cycle in female rats. Brain Research Bulletin 64 449-454. (doi:10.1016/j.brainresbull.2004.10.002) 
Kwon SH, Kang MJ, Huh JS, Ha KW, Lee JR, Lee SK, Lee BS, Han IH, Lee MS, Lee MW et al. 2007 Comparison of oral bioavailability of genistein and genistin in rats. International Journal of Pharmaceutics 337 148-154. (doi:10.1016/j.ijpharm.2006.12.046)

Labinskyy N, Csiszar A, Veress G, Stef G, Pacher P, Oroszi G, Wu J \& Ungvari Z 2006 Vascular dysfunction in aging: potential effects of resveratrol, an anti-inflammatory phytoestrogen. Current Medicinal Chemistry 13 989-996. (doi:10.2174/092986706776360987)

Levy JR, Faber KA, Ayyash L \& Hughes CL Jr 1995 The effect of prenatal exposure to the phytoestrogen genistein on sexual differentiation in rats. Proceedings of the Society for Experimental Biological Medicine 208 60-66.

Li Y \& Tollefsbol TO 2010 Impact on DNA methylation in cancer prevention and therapy by bioactive dietary components. Current Medicinal Chemistry 17 2141-2151. (doi:10.2174/09298671079 1299966)

Li B, Carey M \& Workman JL 2007 The role of chromatin during transcription. Cell 128 707-719. (doi:10.1016/j.cell.2007.01.015)

Lorand T, Vigh E \& Garai J 2010 Hormonal action of plant derived and anthropogenic non-steroidal estrogenic compounds: phytoestrogens and xenoestrogens. Current Medicinal Chemistry 17 3542-3574. (doi:10. 2174/092986710792927813)

Losa SM, Todd KL, Sullivan AW, Cao J, Mickens JA \& Patisaul HB 2011 Neonatal exposure to genistein adversely impacts the ontogeny of hypothalamic kisspeptin signaling pathways and ovarian development in the peripubertal female rat. Reproductive Toxicology 31 280-289. (doi:10.1016/j.reprotox.2010.10.002)

Ma L 2009 Endocrine disruptors in female reproductive tract development and carcinogenesis. Trends in Endocrinology and Metabolism 20 357-363. (doi:10.1016/j.tem.2009.03.009)

MacLusky NJ \& Naftolin F 1981 Sexual differentiation of the central nervous system. Science 211 1294-1302. (doi:10.1126/science.6163211)

Matsukura H, Aisaki K, Igarashi K, Matsushima Y, Kanno J, Muramatsu M, Sudo K \& Sato N 2011 Genistein promotes DNA demethylation of the steroidogenic factor 1 (SF-1) promoter in endometrial stromal cells. Biochemical and Biophysical Research Communications 412 366-372. (doi:10.1016/j.bbrc.2011.07.104)

Medlock KL, Forrester TM \& Sheehan DM 1994 Progesterone and estradiol interaction in the regulation of rat uterine weight and estrogen receptor concentration. Proceedings of the Society for Experimental Biological Medicine 205 146-153.

Medlock KL, Branham WS \& Sheehan DM 1995a Effects of coumestrol and equol on the developing reproductive tract of the rat. Proceedings of the Society for Experimental Biological Medicine 208 67-71.

Medlock KL, Branham WS \& Sheehan DM 1995b The effects of phytoestrogens on neonatal rat uterine growth and development. Proceedings of the Society for Experimental Biological Medicine 208 307-313.

Milligan SR, Khan O \& Nash M 1998 Competitive binding of xenobiotic oestrogens to rat $\alpha$-fetoprotein and to sex steroid binding proteins in human and rainbow trout (Oncorhynchus mykiss) plasma. General and Comparative Endocrinology 112 89-95. (doi:10.1006/gcen.1998. 7146)

Miyagawa S, Buchanan DL, Sato T, Ohta Y, Nishina Y \& Iguchi T 2002 Characterization of diethylstilbestrol-induced hypospadias in female mice. Anatomical Record 266 43-50. (doi:10.1002/ar.10033)

Morley FH, Axelsen A \& Bennett D 1966 Recovery of normal fertility after grazing on oestrogenic red clover. Australian Veterinary Journal 42 204-206. (doi:10.1111/j.1751-0813.1966.tb04690.x)

Morton MS, Arisaka O, Miyake N, Morgan LD \& Evans BA 2002 Phytoestrogen concentrations in serum from Japanese men and women over forty years of age. Journal of Nutrition 132 3168-3171.

Moutsatsou P 2007 The spectrum of phytoestrogens in nature: our knowledge is expanding. Hormones 6 173-193.

Nagao T, Yoshimura S, Saito Y, Nakagomi M, Usumi K \& Ono H 2001 Reproductive effects in male and female rats of neonatal exposure to genistein. Reproductive Toxicology 15 399-411. (doi:10.1016/S08906238(01)00141-1)

Newbold RR, Bullock BC \& McLachlan JA 1990 Uterine adenocarcinoma in mice following developmental treatment with estrogens: a model for hormonal carcinogenesis. Cancer Research 50 7677-7681.
Newbold RR, Hanson RB, Jefferson WN, Bullock BC, Haseman J \& McLachlan JA 1998 Increased tumors but uncompromised fertility in the female descendants of mice exposed developmentally to diethylstilbestrol. Carcinogenesis 19 1655-1663. (doi:10.1093/carcin/19.9.1655)

Newbold RR, Hanson RB, Jefferson WN, Bullock BC, Haseman J \& McLachlan JA 2000 Proliferative lesions and reproductive tract tumors in male descendants of mice exposed developmentally to diethylstilbestrol. Carcinogenesis 21 1355-1363. (doi:10.1093/carcin/21.7.1355)

Newbold RR, Banks EP, Bullock B \& Jefferson WN 2001 Uterine adenocarcinoma in mice treated neonatally with genistein. Cancer Research 61 4325-4328.

Newbold RR, Jefferson WN, Padilla-Banks E \& Haseman J 2004 Developmental exposure to diethylstilbestrol (DES) alters uterine response to estrogens in prepubescent mice: low versus high dose effects. Reproductive Toxicology 18 399-406. (doi:10.1016/j.reprotox. 2004.01.007)

Nikaido Y, Yoshizawa K, Danbara N, Tsujita-Kyutoku M, Yuri T, Uehara N \& Tsubura A 2004 Effects of maternal xenoestrogen exposure on development of the reproductive tract and mammary gland in female CD-1 mouse offspring. Reproductive Toxicology 18 803-811. (doi:10. 1016/j.reprotox.2004.05.002)

North K \& Golding J 2000 A maternal vegetarian diet in pregnancy is associated with hypospadias. The ALSPAC Study Team. Avon Longitudinal Study of Pregnancy and Childhood. BJU International 85 107-113. (doi:10.1046/j.1464-410x.2000.00436.x)

Padilla-Banks E, Jefferson WN, Myers PH, Goulding DR \& Williams CJ 2012 Neonatal phytoestrogen exposure causes hypospadias in female mice. Molecular Reproduction and Development 79 3. (doi:10.1002/ mrd.21395)

Palmer JR, Herbst AL, Noller KL, Boggs DA, Troisi R, Titus-Ernstoff L, Hatch EE, Wise LA, Strohsnitter WC \& Hoover RN 2009 Urogenital abnormalities in men exposed to diethylstilbestrol in utero: a cohort study. Environmental Health 8 37. (doi:10.1186/1476-069X-8-37)

Pan L, Xia X, Feng Y, Jiang C, Cui Y \& Huang Y 2008 Exposure of juvenile rats to the phytoestrogen daidzein impairs erectile function in a doserelated manner in adulthood. Journal of Andrology 29 55-62. (doi:10. 2164/jandrol.107.003392)

Park SY \& Jameson JL 2005 Minireview: transcriptional regulation of gonadal development and differentiation. Endocrinology $\mathbf{1 4 6}$ 1035-1042. (doi:10.1210/en.2004-1454)

Peeters PH, Slimani N, van der Schouw YT, Grace PB, Navarro C, Tjonneland A, Olsen A, Clavel-Chapelon F, Touillaud M, BoutronRuault MC et al. 2007 Variations in plasma phytoestrogen concentrations in European adults. Journal of Nutrition 137 1294-1300.

Prossnitz ER \& Barton M 2009 Signaling, physiological functions and clinical relevance of the $G$ protein-coupled estrogen receptor GPER. Prostaglandins \& Other Lipid Mediators 89 89-97. (doi:10.1016/j. prostaglandins.2009.05.001)

Robinson JD, Judd HL, Young PE, Jones OW \& Yen SS 1977 Amniotic fluid androgens and estrogens in midgestation. Journal of Clinical Endocrinology and Metabolism 45 755-761. (doi:10.1210/jcem-45-4-755)

Roselli CE \& Stormshak F 2010 The ovine sexually dimorphic nucleus, aromatase, and sexual partner preferences in sheep. Journal of Steroid Biochemistry and Molecular Biology 118 252-256. (doi:10.1016/j. jsbmb.2009.10.009)

Ross AE, Marchionni L, Phillips TM, Miller RM, Hurley PJ, Simons BW, Salmasi AH, Schaeffer AJ, Gearhart JP \& Schaeffer EM 2011 Molecular effects of genistein on male urethral development. Journal of Urology 185 1894-1898. (doi:10.1016/j.juro.2010.12.095)

Sakuma Y 2009 Gonadal steroid action and brain sex differentiation in the rat. Journal of Neuroendocrinology 21 410-414. (doi:10.1111/j.13652826.2009.01856.x)

Setchell KD, Gosselin SJ, Welsh MB, Johnston JO, Balistreri WF, Kramer LW, Dresser BL \& Tarr MJ 1987 Dietary estrogens - a probable cause of infertility and liver disease in captive cheetahs. Gastroenterology $93225-233$.

Setchell KD, Zimmer-Nechemias L, Cai J \& Heubi JE 1997 Exposure of infants to phyto-oestrogens from soy-based infant formula. Lancet $\mathbf{3 5 0}$ 23-27. (doi:10.1016/S0140-6736(96)09480-9)

Shanle EK \& Xu W 2011 Endocrine disrupting chemicals targeting estrogen receptor signaling: identification and mechanisms of action. Chemical Research in Toxicology 24 6-19. (doi:10.1021/tx100231n) 
Sharpe RM, Martin B, Morris K, Greig I, McKinnell C, McNeilly AS \& Walker M 2002 Infant feeding with soy formula milk: effects on the testis and on blood testosterone levels in marmoset monkeys during the period of neonatal testicular activity. Human Reproduction 17 1692-1703. (doi:10.1093/humrep/17.7.1692)

Simerly RB 2002 Wired for reproduction: organization and development of sexually dimorphic circuits in the mammalian forebrain. Annual Review of Neuroscience 25 507-536. (doi:10.1146/annurev.neuro.25.112701. 142745)

Singh M, Parent S, Leblanc V \& Asselin E 2011 Resveratrol modulates the expression of PTGS2 and cellular proliferation in the normal rat endometrium in an AKT-dependent manner. Biology of Reproduction 84 1045-1052. (doi:10.1095/biolreprod.110.090076)

Sisk CL \& Zehr JL 2005 Pubertal hormones organize the adolescent brain and behavior. Frontiers in Neuroendocrinology 26 163-174. (doi:10. 1016/j.yfrne.2005.10.003)

de Souza PL, Russell PJ, Kearsley JH \& Howes LG 2010 Clinical pharmacology of isoflavones and its relevance for potential prevention of prostate cancer. Nutrition Reviews 68 542-555. (doi:10.1111/j.17534887.2010.00314.x)

Stillman RJ 1982 In utero exposure to diethylstilbestrol: adverse effects on the reproductive tract and reproductive performance and male and female offspring. American Journal of Obstetrics and Gynecology 142 905-921.

Strom BL, Schinnar R, Ziegler EE, Barnhart KT, Sammel MD, Macones GA, Stallings VA, Drulis JM, Nelson SE \& Hanson SA 2001 Exposure to soybased formula in infancy and endocrinological and reproductive outcomes in young adulthood. Journal of the American Medical Association 286 807-814. (doi:10.1001/jama.286.7.807)

Suetsugi M, Su L, Karlsberg K, Yuan YC \& Chen S 2003 Flavone and isoflavone phytoestrogens are agonists of estrogen-related receptors. Molecular Cancer Research 1 981-991.

Sullivan AW, Hamilton P \& Patisaul HB 2011 Neonatal agonism of ER $\beta$ impairs male reproductive behavior and attractiveness. Hormones and Behavior 60 185-194. (doi:10.1016/j.yhbeh.2011.04.006)

Syme MR, Paxton JW \& Keelan JA 2004 Drug transfer and metabolism by the human placenta. Clinical Pharmacokinetics 43 487-514. (doi:10. 2165/00003088-200443080-00001)

Tan KA, Walker M, Morris K, Greig I, Mason JI \& Sharpe RM 2006 Infant feeding with soy formula milk: effects on puberty progression, reproductive function and testicular cell numbers in marmoset monkeys in adulthood. Human Reproduction 21 896-904. (doi:10.1093/humrep/ dei421)

Tang WY, Newbold R, Mardilovich K, Jefferson W, Cheng RY, Medvedovic M \& Ho SM 2008 Persistent hypomethylation in the promoter of nucleosomal binding protein 1 (Nsbp1) correlates with overexpression of Nsbp1 in mouse uteri neonatally exposed to diethylstilbestrol or genistein. Endocrinology 149 5922-5931. (doi:10. 1210/en.2008-0682)

Thompson LU, Boucher BA, Liu Z, Cotterchio M \& Kreiger N 2006 Phytoestrogen content of foods consumed in Canada, including isoflavones, lignans, and coumestan. Nutrition and Cancer $\mathbf{5 4}$ 184-201. (doi:10.1207/s15327914nc5402_5)

Tou JC, Chen J \& Thompson LU 1998 Flaxseed and its lignan precursor, secoisolariciresinol diglycoside, affect pregnancy outcome and reproductive development in rats. Journal of Nutrition 128 1861-1868.
Umezu T, Yamanouchi H, lida Y, Miura M \& Tomooka Y 2010 Follistatinlike-1, a diffusible mesenchymal factor determines the fate of epithelium. PNAS 107 4601-4606. (doi:10.1073/pnas.0909501107)

Valdes-Dapena MA 1973 The development of the uterus in late fetal life, infancy, and childhood. In The Uterus (International Academy of Pathology Monograph Series), pp 40-67. Ed. HJ Norris. Melbourne, FL: Krieger Pub Co.

Valentin-Blasini L, Blount BC, Caudill SP \& Needham LL 2003 Urinary and serum concentrations of seven phytoestrogens in a human reference population subset. Journal of Exposure Analysis and Environmental Epidemiology 13 276-282. (doi:10.1038/sj.jea.7500278)

Verkasalo PK, Appleby PN, Allen NE, Davey G, Adlercreutz H \& Key TJ 2001 Soya intake and plasma concentrations of daidzein and genistein: validity of dietary assessment among eighty British women (Oxford arm of the European Prospective Investigation into Cancer and Nutrition). British Journal of Nutrition 86 415-421. (doi:10.1079/BJN2001424)

Vilela ML, Willingham E, Buckley J, Liu BC, Agras K, Shiroyanagi Y \& Baskin LS 2007 Endocrine disruptors and hypospadias: role of genistein and the fungicide vinclozolin. Urology 70 618-621. (doi:10.1016/j. urology.2007.05.004)

Visser JA, McLuskey A, Verhoef-Post M, Kramer P, Grootegoed JA \& Themmen AP 1998 Effect of prenatal exposure to diethylstilbestrol on Mullerian duct development in fetal male mice. Endocrinology 139 4244-4251. (doi:10.1210/en.139.10.4244)

Wade PA \& Archer TK 2006 Epigenetics: environmental instructions for the genome. Environmental Health Perspectives 114 A140-A141. (doi:10. 1289/ehp.114-a140)

Watson CS, Alyea RA, Jeng YJ \& Kochukov MY 2007 Nongenomic actions of low concentration estrogens and xenoestrogens on multiple tissues. Molecular and Cellular Endocrinology 274 1-7. (doi:10.1016/j.mce. 2007.05.011)

Wisniewski AB, Klein SL, Lakshmanan Y \& Gearhart JP 2003 Exposure to genistein during gestation and lactation demasculinizes the reproductive system in rats. Journal of Urology 169 1582-1586. (doi:10.1097/01.ju. 0000046780.23389.e0)

Wisniewski AB, Cernetich A, Gearhart JP \& Klein SL 2005 Perinatal exposure to genistein alters reproductive development and aggressive behavior in male mice. Physiology \& Behavior 84 327-334. (doi:10. 1016/j.physbeh.2004.12.008)

Wohlfahrt-Veje C, Main KM \& Skakkebaek NE 2009 Testicular dysgenesis syndrome: foetal origin of adult reproductive problems. Clinical Endocrinology 71 459-465. (doi:10.1111/j.1365-2265.2009.03545.x)

Wolff MS, Britton JA, Boguski L, Hochman S, Maloney N, Serra N, Liu Z, Berkowitz G, Larson S \& Forman J 2008 Environmental exposures and puberty in inner-city girls. Environmental Research 107 393-400. (doi:10.1016/j.envres.2008.03.006)

Wu MV \& Shah NM 2011 Control of masculinization of the brain and behavior. Current Opinion in Neurobiology 21 116-123. (doi:10.1016/j. conb.2010.09.014)

Young WC, Goy RW \& Phoenix CH 1964 Hormones and sexual behavior. Science 143 212-218. (doi:10.1126/science.143.3603.212)

Received 3 October 2011

First decision 4 November 2011

Accepted 5 January 2012 